Jurnal Medicoeticolegal dan Manajemen Rumah Sakit, 6 (1): 1-8, April 2017

Website: http://journal.umy.ac.id/index.php/mrs

DOI: $10.18196 / \mathrm{jmmr} .6121$

\title{
Identifikasi Faktor yang Mempengaruhi Total Biaya Inventori Obat-obatan Golongan A di Rumah Sakit Swasta Tipe B di Jakarta Tahun 2015
}

\author{
Agnes Susanto*, Erna Kristin**, Agastya*** \\ *Penulis Korespondensi: agnes.susanto@gmail.com \\ *Mahasiswa Pascasarjana Program Manajemen Rumah Sakit Ilmu Kesehatan Masyarakat Universitas Gadjah Mada \\ **Staf Pengajar Fakultas Kedokteran Universitas Gadjah Mada
}

***Staf Pengajar Fakultas Ekonomi Universitas Gadjah Mada

\begin{tabular}{l}
\hline INDEXIN G \\
\hline Keywords: \\
Total Inventory Cost; \\
Inventory Strategy; \\
ABC Analysis; \\
Economic Order \\
Quantity; \\
Reorder Point
\end{tabular}

\begin{abstract}
A B S T R A C T
Inventory is one of the crucial components in hospital operations. The value o inventory may range up until $25 \%$ of the total cost of the hospital operation. Inventory optimization may save up to $10 \%$ in the minimum. There is a lot of drugs circulation in hospital. There is always a chance for a mistake. A tight control of inventory is necessary for hospital managers to minimize any potential waste. A saving directive for $20 \%$ drugs which consume $70 \%$ of the total cost will boost the hospital efficiency. A lot of factors influences hospital inventory and how managers strategize for the inventory. Some identified factors are order frequency, order quantity, unit price, and other hidden costs. The purpose of this research is to prove the correlation of each factor and how they influence the total inventory cost. To follow up the result, henceforth a model of simulation by calculating Economic Order Quantity and Reorder Point, the research may help hospital managers in modifying the strategy of managing hospital inventory for the next year period. This study aims to identify the factors which influence total inventory cost in managing group A drugs at private type B hospital, Jakarta. This study using observational analytics, cross-sectional study.
\end{abstract}

Kata kunci:

Total Biaya Inventori; Strategi Inventori;

ABC Analysis;

Economic Order

Quantity;

Reorder Point;
Inventori adalah salah satu komponen dari operasional rumah sakit dan nilainya bisa mencapai $25 \%$. Optimalisasi inventori di rumah sakit bisa memberikan penghematan hingga sebesar minimal $10 \%$. Obat-obatan yang beredar di rumah sakit sangatlah banyak sehingga dibutuhkan sebuah kendali inventori untuk bisa memprioritaskan usaha kendali inventori ini. Dengan penghematan pada $20 \%$ obat yang berkontribusi sebesar $70 \%$ dari total biaya membuat rumah sakit semakin efisien. Inventori dipengaruhi oleh banyak faktor, misalnya faktor yang ada di bawah kendali unit farmasi seperti strategi pengadaan dan strategi inventori atau penyediaan. Faktor-faktor yang berperan dalam strategi inventori adalah frekuensi pemesanan, jumlah pesanan, harga satuan obat serta adanya biaya lainnya yang terselubung. Penelitian ini ditujukan untuk membuktikan adanya hubungan yang signifikan antara faktor-faktor tersebut dengan biaya inventori pada rumah sakit tempat penelitian sehingga bisa dibuatkan simulasi model penghematan dengan penghitungan Economic Order Quantity dan Reorder Point yang akan memodifikasi strategi jumlah pemesanan dan frekuensi pemesanan obat dalam 1 tahun. Penelitian ini bertujuan untuk mengidentifikasi faktor yang mempengaruhi total biaya inventori pada pengelolaan obat-obatan golongan A di Rumah Sakit Swasta Tipe B, Jakarta. Metode yang digunakan adalah observasional analitik, cross-sectional study.

(C) 2017 JMMR. All rights reserved

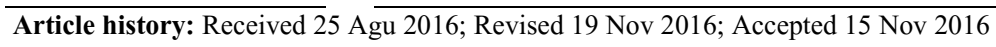

\section{PENDAHULUAN}

Pengelolaan perbekalan farmasi sering menjadi sorotan. Hasil survei yang dilakukan oleh Amerian Society of Health System Pharmacist (ASHP) di tahun 2000, dilakukan survei kepada para manajer rumah sakit dan hasilnya perbekalan farmasi adalah urutan ketujuh teratas yang harus dibenahi. Isu pengelolaan obat ini penting karena biaya obat mengambil porsi besar dalam anggaran rumah sakit. Selain itu, nominalnya juga terus meningkat dari tahun ke tahun. 1

Penelitian di Thailand, didapatkan bahwa biaya instalasi farmasi adalah sebesar 25\% sampai $27 \%$ dari total biaya pengeluaran rumah sakit. $\stackrel{2}{ }$ Berdasarkan data 
penelitian, anggaran operasional RSU Cianjur 1998/1999 biaya obat adalah sebesar 17,4\% dari biaya operasional RSU tersebut. ${ }^{3}$ Penelitian yang dilakukan oleh Azis dan kawan-kawan pada tahun 2002 di Rumah Sakit Umum Kabupaten Sidoarjo didapatkan bahwa biaya obat mencapai $43 \%$ dari total biaya operasional rumah sakit itu. 2 Selain itu, penelitian yang dilakukan oleh Rachmania dan Basri tahun 2013 pada rumah sakit umum di Bandung, obat-obatan onkologi saja menghabiskan anggaran hingga $\mathrm{Rp} 581.351 .138$,- dalam periode 6 bulan. . $^{-}$

Pengelolaan inventori yang optimal bisa memberikan penghematan biaya penyelenggaraan perbekalan obat sampai dengan 10\%. Biaya operasional pengelolaan rantai suplai obat pada rumah sakit bisa mencapai $40 \%$ dari total biaya operasional oleh karena itu sangat penting untuk sebuah rumah sakit melakukan perbaikan

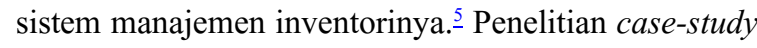
di rumah sakit nasional pada tahun 2013 juga memberikan hasil adanya penghematan sebesar 50\% dari biaya sesungguhnya bilamana dilakukan pergantian kebijakan pengelolaan perbekalan obat onkologi dengan metode continuous review (s,Q). ${ }^{4}$

Perlu dipahami bahwa banyak faktor yang mempengaruhi biaya inventori. Salah satunya, beberapa faktor yang dapat mempengaruhi total cost inventory adalah:- (a) Harga per unit obat; (b) Frekuensi pemesanan dan total biaya pembelian; dan (c) Adanya biaya yang kasat mata dan biaya terselubung. Dalam melakukan pengadaan obat, seperti yang dijelaskan di atas bahwa untuk melakukan manajemen inventori yang efisien, faktor-faktor yang berperan adalah safety stock, jumlah obat per pemesanan, frekuensi pemesanan ulang. - Jumlah obat dalam gudang perbekalan akan meningkatkan biaya penyimpanan sehingga perlu dikompromikan dengan frekuensi pemesanan yang lebih sering untuk menurunkan biaya penyimpanan., ${ }^{2,7}$ Namun, frekuensi pemesanan yang meningkat akan meningkatkan biaya pembelian (purchasing cost) 6 Biaya ini seperti yang dijelaskan di atas juga umumnya selalu naik setiap tahunnya. $-\underline{6}$

Kendali inventori guna menekan biaya total inventori bisa dilakukan dengan berbagai metode, salah satu metode yang paling umum digunakan dalam melakukan kendali terhadap inventori adalah dengan melakukan $A B C$ analysis. Analisa $\mathrm{ABC}$ ini berguna dalam penentuan strategi pemilihan obat (selection), pengadaan (procurement), distribusi dan mendorong penggunaan obat secara rasional. - -9,, 10 Dalam strategi pengadaan, analisis $\mathrm{ABC}$ bisa membantu manajer dalam menentukan frekuensi pemesanan, mencari sumber atau penjual yang menjual obat-obat golongan A dengan harga yang lebih murah, pemantauan status pemesanan agar bisa menghindari terjadinya kehabisan obat yang menyebabkan biaya lebih besar akibat pembelian mendadak yang umumnya lebih mahal, pemantauan prioritas pelaksanaan strategi pengadaan obat dan pemantauan terhadap perencanaan pengadaan obat dan pembelian nyata. ${ }^{6-9}$ - Dalam pemantauan terhadap frekuensi pemesanan, pemesanan obat-obatan golongan A yang lebih sering dan dalam jumlah yang lebih sedikit akan mengurangi biaya penyimpanan obat (inventory-holding cost). $\cdot$

Metode lain untuk mengetahui kinerja pengelolaan perbekalan obat rumah sakit adalah dengan mteode VEN yang mengklasifikasikan obat-obatan dalam kategori vital, essential atau nonessential. Golongan VEN bisa menggunakan panduan klasifikasi VEN yang dikeluarkan oleh Badan Kesehatan Dunia atau $\mathrm{WHO}^{11}$ atau daftar obat esensial nasional 12 yang dikeluarkan oleh Kemenkes RI. Analisis kelas terapi obat juga membantu manajer farmasi rumah sakit untuk memantau peredaran obat dan kegunaan terapinya. Selain itu, analisis ini juga bisa memberikan masukan kelompok obat yang memberikan efek terapi terbaik dan harga yang terjangkau. $\underline{6}$

\section{METODE PENELITIAN}

Tujuan dari penelitian ini adalah untuk mencari tahu faktor-faktor yang mempengaruhi total biaya inventori dan hubungannya. Faktor yang dimaksud adalah frekuensi pemesanan (order frequency), jumlah pesanan (order quantity), biaya terselubung (hidden cost), yaitu biaya obat rusak, kadaluwarsa atau kesalahan obat lainnya.

Penelitian ini adalah penelitian jenis observasional dengan desain deskriptif menggunakan pendekatan studi cross sectional. Penelitian menggunakan data sekunder yaitu data pemakaian obat bulanan selama tahun 2015 dan rincian pemesanan obat selama periode 1 tahun. Kelompok obat yang menjadi subjek penelitian adalah semua obat golongan A.

Tujuan lain dari penelitian ini adalah menghitung simulasi perencanaan inventori dengan menggunakan 
model matematika, Economic Order Quantity (EOQ) untuk kelompok obat yang dijadikan subjek penelitian serta menentukan safety stock dan reorder point obatobatan tersebut.

\section{HASIL}

Dari data pemakaian obat rumah sakit yang diambil dari rekapitulasi transaksi penjualan obat periode bulan Januari hingga Juni 2015, didapatkan total 2052 jenis obat dengan total penggunaan senilai Rp 25,749,687,371,-.
Analisis kategori VEN digolongkan berdasarkan Daftar Obat Esensial Nasional (DOEN) tahun 2013. 11 Pengklasifikasian kelas terapi dilakukan berdasarkan kode ATC WHOCC basis data. ${ }^{13}$ Analisis data rincian pemesanan selama periode 1 tahun (Juni 2014 - Juni 2015). untuk obat-obat golongan A, frekuensi pemesanan (order frequency) dalam periode 1 tahun, jumlah pesanan obat (order quantity) dalam 1 kali

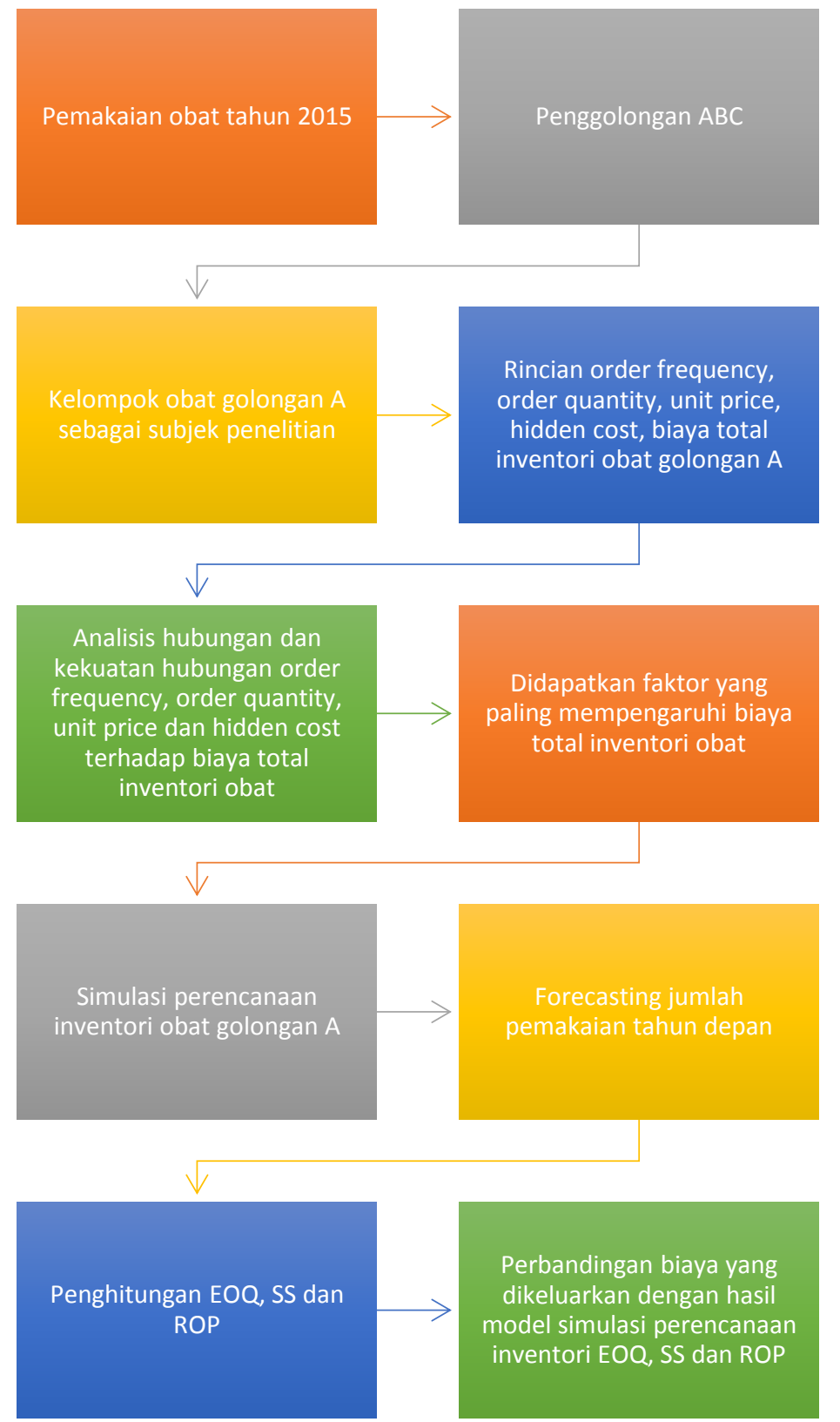

EOQ: Economic Order Quantity; SS: Safety Stock; ROP: Reorder Point

\section{Gambar 1. Bagan Alur Kerja Penelitian}


Tabel 1. Analisis ABC Berdasarkan Jumlah Item dan Biaya Obat

Bulan Januari Hingga Juni 2015

\begin{tabular}{lcccc}
\hline Golongan & \multicolumn{2}{c}{ Item Obat } & \multicolumn{2}{c}{ Biaya } \\
\hline & Jumlah & Persentase (\%) & Jumlah (Rp) & Persentase (\%) \\
\hline A & 129 & $6,28 \%$ & 18.061 .603 .233 & $70,14 \%$ \\
B & 238 & $11,59 \%$ & 5.115 .006 .389 & $19,87 \%$ \\
C & 1685 & $82,13 \%$ & 2.573 .077 .744 & $9.99 \%$ \\
Total & 2052 & $100 \%$ & 25.749 .687 .371 & $100 \%$ \\
\hline
\end{tabular}

Tabel 2. Analisis VEN pada Obat Golongan A Berdasarkan Data Bulan Januari Hingga Juni 2015

\begin{tabular}{lcccc}
\hline Kategori & \multicolumn{2}{c}{ Item Obat } & \multicolumn{2}{c}{ Biaya } \\
\hline & Jumlah & Persentase (\%) & Jumlah (Rp) & Persentase (\%) \\
\hline Vital & 17 & $13,18 \%$ & 2.717 .271 .289 & $15,04 \%$ \\
Esensial & 43 & $33,33 \%$ & 7.015 .167 .512 & $38,84 \%$ \\
& & & & \\
Nonesensial & 69 & $53,49 \%$ & 8.329 .164 .432 & $46,12 \%$ \\
Total & 129 & $100 \%$ & 18.061 .603 .233 & $100 \%$ \\
\hline
\end{tabular}

\section{Grafik Sebaran Jumlah Jenis Obat Golongan A Bulan Januari Hingga Juni 2015 Berdasarkan Pembagian Kelas Terapi Obat}

25

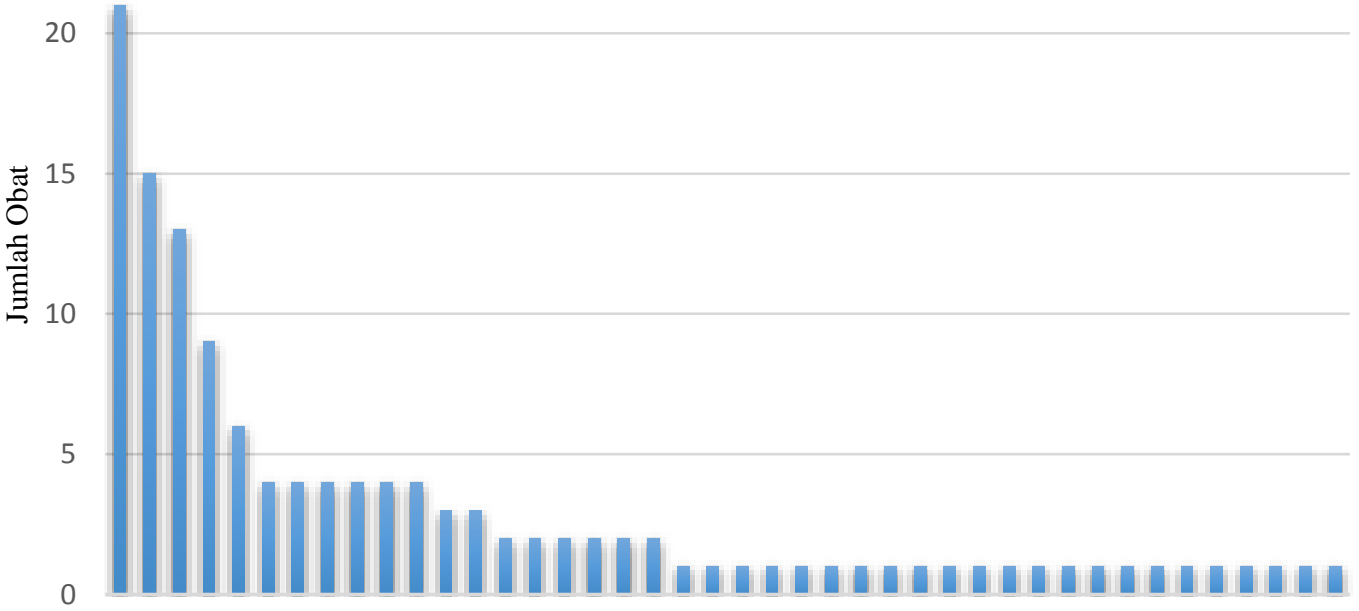

J01 A02 L01 A04 B01 A10 A05 C01 A03 C10 D06 R06 J05 V08 C03 R03 V06 M03M09 N06 J07 Jenis Kelas Terapi Obat Berdasarkan Kode ATC

Kode ATC:

J01: Antibacterials for systemic use; B05: Blood substitutes and perfusion solutions; A02: Drugs for acid related disorders; N01: Anesthetics; L01:Antineoplastic agents; C09: Agents acting on the reninangiotensin system; A04: antiemetics and antinauseants; M01: anti-inflammatory and antirheumatic products; B01: antithrombotic agents; C08: Calcium channel blockers; A10: Drugs used in diabetes; J04: Antimycobacterials; A05: Bile and liver therapy; N02: Analgesics; C01: Cardiac therapy; D07: Corticosteroids, dermatological preparations; A03: Drugs for functional gastrointestinal disorder; L03: 
Immunostimulants; C10: Lipid modifying agents; B03: Antianemic preparations; D06: Antibiotics and chemotherapeutics for dermatological use; N03: Antiepileptics, R06: Antihistamines for systemic use; J02: Antimycotics for systemic use; J05: Antivirals for systemic use; C07: Beta blocking agents; V08: Contrast media; H02: Corticosteroids for systemic use; C03: Diuretics; A06: Drugs for constipation; R03: Drugs for obstructive airway diseases; L02: Endocrine therapy; V06: General nutrients; J06: Immune sera and immunoglobulins; M03: Muscle relaxants; R01: Nasal preparations; M09: Other drugs for disorder of the musculo-skeletal system; N07: Other nervous system drugs; N06: psychoanaleptics; G04: Urologicals; J07: Vaccines; A11: Vitamins

Gambar 5. Grafik Jumlah Jenis Obat Golongan A Berdasarkan Jenis Kelas Terapi Obat Menurut WHOCC ${ }^{13}$

Tabel 3. Daftar 5 Besar Kelompok Obat Berdasarkan Kelas Terapi dengan Biaya Pemakaian Tertinggi

\begin{tabular}{lllll}
\hline No & Kelas terapi & Jumlah Obat & Biaya (Rp) & Persentase \% \\
\hline 1 & Antibacterials for systemic use & 21 & 4.090 .581 .675 & $22.65 \%$ \\
2 & Blood substitutes and perfusion solutions & 15 & 2.481 .582 .479 & $13.74 \%$ \\
3 & Drugs for acid related disorders & 13 & 2.183 .061 .972 & $12.09 \%$ \\
4 & Anesthetics & 9 & 1.363 .389 .583 & $7.55 \%$ \\
5 & Drugs used in diabetes & 4 & 811.521 .873 & $4.49 \%$ \\
\hline
\end{tabular}

Tabel 4. Hasil Analisis Hubungan Korelasi Variabel Independen dan Variabel Dependen

\begin{tabular}{lllllllll}
\hline Variabel Dependen & \multicolumn{10}{l}{ Variabel Independen } \\
\hline Total inventory cost & \multicolumn{2}{l}{ Unit Price } & \multicolumn{2}{l}{ Order Quantity } & \multicolumn{1}{l}{ Order Frequency } & \multicolumn{2}{l}{ Hidden cost } \\
\hline Metode: & r & Sig & r & Sig & r & Sig & r & Sig \\
Korelasi Spearman & $-0,02$ & 0,827 & $\mathbf{0 , 2 4 2}$ & $\mathbf{0 , 0 2 6}$ & $\mathbf{0 , 6 9 5}$ & $\mathbf{0 , 0 0 0 5}$ & $-0,037$ & 0,735 \\
Korelasi Pearson & $-0,06$ & 0,559 & 0,113 & 0,302 & $\mathbf{0 , 6 1 3}$ & $\mathbf{0 , 0 0 0 5}$ & $-0,053$ & 0,631 \\
\hline
\end{tabular}

Tabel 5. Hasil Analisis Multivariat dengan Permodelan Regresi Linear

\begin{tabular}{|c|c|c|c|c|}
\hline Variabel & B & Std. Error & Beta & Sig \\
\hline (Constant) & -3249205.413 & 3513163.493 & & 0.358 \\
\hline $\begin{array}{l}\text { Frekuensi } \\
\text { pemesanan }\end{array}$ & 493361.331 & 69784.305 & 0.613 & 0 \\
\hline
\end{tabular}

pemesanan, harga satuan obat (unit price) dan biaya total obat rusak, kadwaluwarsa atau kesalahan pengiriman dilakukan dengan SPSS versi 17. Dari 129 buah obat yang termasuk dalam golongan A, hanya berhasil didapatkan data rincian pesanan lengkap untuk 85 jenis obat. Sisa 44 jenis obat tidak berhasil didapatkan lengkap sehingga dalam analisis dianggap sebagai data missing.

Analisis korelasi menggunakan dua metode yaitu statistic parametrik (korelasi pearson) dan statistic non parametrik (korelasi spearman) untuk analisa bivariat. Dengan korelasi Spearman, hasil analisis menunjukkan volume pemesanan dan frekuensi pemesanan berhubungan signifikan $(\mathrm{Sig}<0,05)$ dengan total inventory cost.
Keduanya berhubungan positif dengan total inventory cost, semakin besar frekuensi dan volume pemesanan semakin besar pula total inventory cost. Koefisien korelasi volume pemesanan menunjukkan korelasi sangat lemah dengan total inventory cost. Sedangkan koefisien korelasi frekuansi pemesanan menunjukkan korelasi kuat dengan total inventory cost.

Hasil analisis korelasi Pearson, hanya frekuensi pemesanan yang berhubungan signifikan dengan total inventory cost. Koefisien korelasi sebesar 0,613 menunjukkan ada korelasi kuat antara frekuansi pemesanan dengan total inventory cost. Analisis multivariat terhadap dilakukan dengan menggunakan permodelan regresi linear. Dalam permodelan regresi 
linear hanya variabel frekuensi pemesanan yang berhubungan signifikan $($ sig<0,05) dengan total inventory cost. Setiap kenaikan satu kali frekuensi pemesanan akan meningkatkan total inventory cost sebesar Rp 493.361,-.

Data untuk peramalan penggunaan obat golongan A untuk periode 12 bulan berikutnya dilakukan berdasarkan data pemakaian bulanan obat-obat golongan A selama bulan Januari 2015 hingga Juni 2015. Peramalan dilakukan dengan menggunakan. Metode Trend Analysis, Additive Decomposition dan Multiplicative Decomposition dalam software POM versi 3 untuk Windows.

Peramalan menggunakan ketiga metode di atas karena hasil ramalan dapat memprediksikan sampai dengan 12 periode mendatang. Hasil peramalan yang digunakan untuk analisis lebih lanjut adalah metode peramalan dengan nilai Mean Absolute Deviation (MAD) yang terkecil.

Dari hasil peramalan penggunaan 85 jenis obat golongan A untuk 12 periode mendatang, didapatkan perkiraan jumlah pemakaian 12 bulan mendatang. Data ini diperlukan untuk simulasi menghitung nilai

Tabel 6. Daftar 10 Obat dengan Ramalan Jumlah Pemakaian Terbanyak untuk Periode 12 Bulan Mendatang dan Nilai Economic Order Quantity (EOQ), Safety Stock serta Reorder Point

\begin{tabular}{|c|c|c|c|c|c|c|}
\hline No & Nama Barang & $\begin{array}{l}\text { Kandungan } \\
\text { Obat }\end{array}$ & $\begin{array}{l}\text { Ramalan } \\
\text { Pemakaian }\end{array}$ & EOQ & $\begin{array}{l}\text { Safety } \\
\text { Stock }\end{array}$ & $\begin{array}{l}\text { Reorder } \\
\text { Point }\end{array}$ \\
\hline 1 & Clopidogrel 75mg tab. (G) & Clopidogrel & 575.105 & 37.137 & 2.637 & 5.832 \\
\hline 2 & $\begin{array}{l}\text { Ecosol RL infus 500ml (B. } \\
\text { Braun) }\end{array}$ & Ringer lactat & 223.910 & 3.674 & 1.030 & 3.121 \\
\hline 3 & $\begin{array}{l}\text { Ecosol } \mathrm{NaCl} 0.9 \% \text { inf } 100 \mathrm{ml} \\
\text { (B.Braun) }\end{array}$ & $\mathrm{NaCl}$, Water & 199.692 & 3.762 & 925 & 2.840 \\
\hline 4 & Pumpitor 20mg caps & Omeprazole & 189.270 & 2.241 & 870 & 1.701 \\
\hline 5 & Merimac 450mg capl. & Rifampicin & 151984 & 4.305 & 746 & 2.880 \\
\hline 6 & Diovan $160 \mathrm{mg}$ tab & Valsartan & 143.134 & 1.752 & 659 & 1.653 \\
\hline 7 & $\begin{array}{l}\text { Ecosol } \mathrm{NaCl} 0,9 \% \text { inf. } 1.000 \mathrm{ml} \\
\text { (B.Braun) }\end{array}$ & $\mathrm{NaCl}$, water & 129.085 & 2.266 & 595 & 1.644 \\
\hline 8 & $\begin{array}{l}\text { Ecosol } \mathrm{NaCl} \text { 0,9\% inf. 500ml } \\
\text { (B.Braun) }\end{array}$ & $\mathrm{NaCl}$, water & 90.473 & 2.433 & 421 & 1.161 \\
\hline 9 & Sotatic $5 \mathrm{mg} / \mathrm{ml}$ inj $2 \mathrm{ml}$ & Metoclopramide & 90.442 & 2.565 & 420 & 1.145 \\
\hline 10 & Valemia $10 \mathrm{mg}$ fc tab & Simvastatin & 79.425 & 1.743 & 366 & 832 \\
\hline
\end{tabular}

monia tidak spesifik, demam berdarah dengue, demam typhoid, tuberkulosis paru, diabetes non-insulin dependen, gangguan jantung atersklerotik, hipertensi tanpa gagal jantung kongestif dan hipertensi primer.
Economic Order Quantity dan Reorder Point dari obatobat tersebut.

\section{Pembahasan}

Hasil penelitian menunjukkan bahwa hanya sebesar $6,28 \%$ obat yang beredar di rumah sakit adalah obat golongan A. Dan dari 129 obat ini 13,18\% adalah obat vital dan 33,33\% adalah obat esensial. Hasil analisis kelas terapi didapatkan kelas terapi obat yang menggunakan biaya porsi terbesar adalah kelas terapi antibiotik sistemik, yaitu sebesar Rp 4.090.581.675,atau $22,65 \%$ dari total biaya golongan $\mathrm{A}$, kemudian diikuti oleh kelas terapi cairan perfusi dan pengganti darah sebesar Rp 2.481.582.479,- atau 13,74\% dan ketiga tertinggi adalah kelas terapi obat gangguan asam lambung menempati posisi ketiga teratas dengan 12,09\% atau Rp 2.183.061.972,--

Sebaran obat golongan A berdasarkan kelompok terapi sudah sesuai dengan sebaran penyakit terbanyak rumah sakit baik di instalasi rawat inap maupun instalasi rawat jalan, yaitu penyakit gagal ginjal kronis, diare dan gastroenteritis akibat infeksi bakteri, pneu-

Data total inventory cost tidak didapatkan oleh peneliti karena tidak ada data. Oleh karena itu dilakukan simulasi penghitungan total inventory cost. Simulasi perhitungan ini didasarkan persentase suatu biaya obat terhadap total keseluruhan biaya obat. 
Biaya capital cost juga diasumsikan berdasarkan denah gudang obat dan harga pasar sewa tanah dan bangunan berikut listrik dan air pada tahun 2015 di wilayah yang sama.

Hal ini yang memberikan hasil analisis bivariat pada penelitian ini hanya variabel frekuensi pemesanan (order frequency) dan volume pesanan (order quantity) yang berpengaruh secara signifikan terhadap total biaya inventori. Variabel lainnya, harga per satuan obat dan biaya terselubung yaitu biaya obat rusak atau kadaluwarsa atau salah kirim ternyata tidak mempengaruhi total biaya perbekalan.

Harga per satuan obat menjadi tidak berpengaruh signifikan terhadap total biaya inventori karena dari rekapitulasi riwayat pemesanan obat selama periode Juni 2014 hingga Juni 2015 jumlah pesanan obat-obat tidak mengalami banyak variasi. Volume pesanan ratarata sama setiap kali pemesanan, tidak ada pesanan dalam jumlah besar. Hal ini menyebabkan harga per satuan obat per pemesanan tidak jauh berbeda.

Biaya total untuk obat rusak, obat kadaluwarsa dan obat yang salah kirim juga tidak signifikan terhadap total biaya inventori karena data atas biaya ini kurang tercatat dengan baik. Catatan hanya berdasarkan buku log petugas bagian penyimpanan. Hasil wawancara juga didapatkan bahwa manajemen penyimpanan juga masih manual dan belum tersistematika dengan baik. Selain itu, bagian Gudang rumah sakit juga belum terintegrasi dengan sistem informasi rumah sakit.

Analisis hubungan korelasi juga didapatkan arah hubungan yang positif antara frekuensi pemesanan dengan total biaya inventori. Perbedaan dengan teori ini disebabkan karena data total inventory cost adalah hasil simulasi sehingga kurang akurat.

Pada penghitungan biaya penyimpanan per satuan obat, didapatkan rata-rata biaya penyimpanan obat adalah sebesar $6 \%$ dari harga satuan obat. Biaya penyimpanan ini jauh lebih rendah dibandingkan dari beberapa penelitian serupa. Penelitian oleh Priatna tahun 2009 di rumah sakit umum area Tangerang menyatakan bahwa biaya penyimpanan per satuan obat adalah $20 \%$ dari harga unit satuan obat. .4 Penelitan lainnya oleh Mulyardewi tahun 2010 di rumah sakit umum di Jakarta mengutip bahwa biaya penyimpanan per satuan obat adalah $20 \%$ dari harga unit satuan obat. $\frac{15}{}$ Namun, biaya penyimpanan dari hasil penelitan ini lebih tinggi dibandingkan penelitian oleh Indrawati tahun 2012 yang mengasumsikan perhitungan besar biaya penyimpanan adalah $3,048 \%$ per satuan harga obat. $\underline{16}$

Peramalan kebutuhan masa mendatang yang dilakukan bagian Farmasi rumah sakit untuk obat-obat golongan fast moving atau obat golongan $\mathrm{A}$ adalah didasarkan pada riwayat pemakaian masa lampau dalam periode 15 hari untuk memprediksikan kebutuhan di periode 15 hari berikutnya dan ditambahkan dengan kebutuhan safety stock yang dihitung sebagai kebutuhan untuk 5 hari. Pemesanan obat-obat golongan fast moving ini dilakukan secara periodik setiap 15 hari. Jumlah atau volume pemesanan disesuaikan dengan sisa stok yang ada di gudang.

Perbandingan biaya antara perencanaan kebutuhan obat dengan peramalan metode yang dianut oleh rumah sakit dan dengan peramalan metode matematika tidak bisa didapatkan dikarenakan kehilangan data dari pihak rumah sakit. Penelitian ini tidak dapat menyimpulkan apakah terjadi penghematan atau pemborosan. Selain itu penelitian ini juga tidak dapat menyimpulkan metode peramalan mana yang lebih tepat untuk obat-obat golongan A.

Kendala yang dihadapi dalam penelitian ini sehingga terjadi keterbatasan pada penelitian ini adalah set data yang diberikan tidak lengkap dan berupa data harian, dokumentasi laporan kegiatan pengelolaan perbekalan farmasi kurang baik, sistematika pencatatan dan pelaporan belum dipahami benar antar bagian farmasi, keuangan dan informasi teknologi (IT) rumah sakit, pemindahan lokasi gudang obat di tahun 2016 awal.

\section{SIMPULAN}

Dalam penelitian ini, Order frequency dan order quantity terbukti mempengaruhi total inventory cost obat golongan A di rumah sakit. Namun, unit price dan biaya hidden cost akibat obat rusak, obat kadaluwarsa dan obat salah kirim tidak terbukti mempengaruhi total inventory cost.

Dalam penelitian ini didapatkan bahwa arah hubungan frekuensi pemesanan dengan total inventory cost adalah positif. Dengan kata lain, dalam penelitian ini didapatkan bahwa peningkatan frekuensi pemesanan akan meningkatkan total inventory cost, bukan sebaliknya seperti pada hipotesa dan studi literatur. Namun, hasil ini masih perlu dibuktikan lebih lanjut 
pada penelitian lain pada rumah sakit yang sama dengan set data yang lain yang lebih baik.

\section{DAFTAR PUSTAKA}

1. ASHP Guidelines on Medication Cost Management Strategies for Hospitals and Health Systems. American Journal of Health-System Pharmacy. 2008;65(14):1368-1384.

2. Laeiddee C. Improvement of Reorder Point for Drug Inventory Management at Ramathibodi Hospital [Postgraduate]. Mahidol University; 2010.

3. Azis S, R S H, M J H. Penyusunan pedoman evaluasi manajemen biaya obat dan biaya riil pengobatan. Bul Penel Kesehatan. 2002;30(2):6980.

4. Nurul Rachmania IHasan Basri M. Pharmaceutical Inventory Management Issues in Hospital Supply Chains. Management. 2013;3(1):1-5.

5. Darling MWise S. Not Your Father's Supply Chain. Materials Management in Health Care. 2010;19(4):30.

6. Barraclough AClark M. Managing Procurement. In: Embrey MRyan M, ed. by. Managing Access to Medicines and Health Technologies. 1st ed. Arlington, VA: Management Sciences for Health; 2012. p. 18.1-18.27.

7. Dias V. Inventory Management. In: Embrey MRyan M, ed. by. Managing Access to Medicines and Health Technologies. 1st ed. Arlington, VA: Management Sciences for Health; 2012. p. 23.123.24.

8. Rankin J. Analyzing and Controlling Pharmaceutical Expenditures. In: Embrey MRyan M, ed. by. Managing Access to Medicines and Health Technologies. 1st ed. Arlington, VA: Management Sciences for Health; 2012. p. 40.140.33 .

9. Wandalkar P, Pandit P, Zite A. ABC and VED analysis of the drug store of a tertiary care teaching hospital. Indian Journal of Basic and Applied Medical Research. 2013;3(1):126-131.

10. Junita I, Sari RK. ABC-VED Analysis and Economic Order Interval ( EOI ) -Multiple Items for Medicines Inventory Control in Hospital. 2012:678-89

11. WHO Model Lists of Essential Medicines [Internet]. World Health Organization. 2016 [cited 26 June 2016]. Available from: http://www.who.int/medicines/publications/essen tialmedicines/en/index.html

12. Kementerian Kesehatan Republik Indonesia. Keputusan Menteri Kesehatan Tentang Daftar Obat Esensial Nasional 2013. Jakarta: Kementerian Kesehatan Republik Indonesia; 2013 p. 24-46.

13. Guidelines for ATC classification and DDD assignment 2013. 16th ed. Oslo: WHO Collaborating Centre for Drug Statistics Methodology; 2012.

14. Indrawati N. Analisis pengendalian persediaan Antibiotik di RSIA Budi Kemuliaan tahun 2011 [Postgraduate]. Universitas Indonesia, Fakultas Kesehatan Masyarakat; 2012.

15. Priatna H. Analisis Perencanaan dan Pengendalian Obat Kelompok A Pada Analisa ABC di Rumah Sakit Melati Tangerang Tahun 2009 [Postgraduate]. Universitas Indonesia, Fakultas Kesehatan Masyarakat; 2010.

16. Mulyardewi I. Analisis Perencanaan dan Pengendalian Obat di RSU Zahirah Jakarta Tahun 2010 [Postgraduate]. Universitas Indonesia, Fakultas Kesehatan Masyarakat; 2010. 